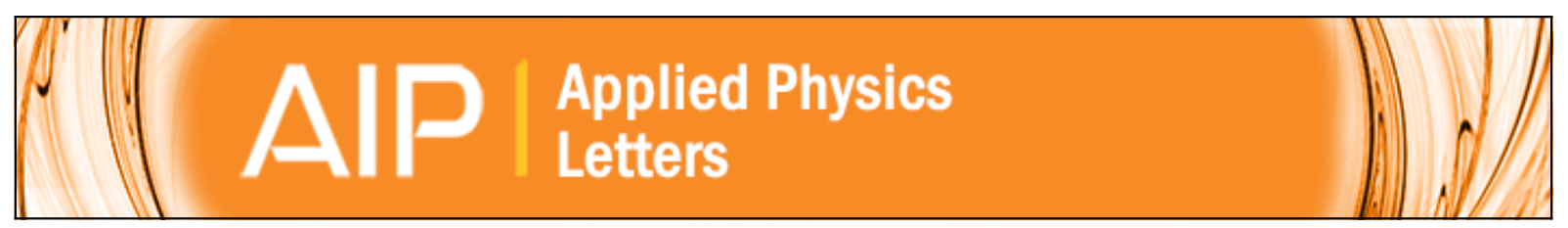

\title{
Automated single cell sorting and deposition in submicroliter drops
}

Rita Salánki, Tamás Gerecsei, Norbert Orgovan, Noémi Sándor, Beatrix Péter, Zsuzsa Bajtay, Anna Erdei, Robert Horvath, and Bálint Szabó

Citation: Applied Physics Letters 105, 083703 (2014); doi: 10.1063/1.4893922

View online: http://dx.doi.org/10.1063/1.4893922

View Table of Contents: http://scitation.aip.org/content/aip/journal/apl/105/8?ver=pdfcov

Published by the AIP Publishing

\section{Articles you may be interested in}

The construction of an interfacial valve-based microfluidic chip for thermotaxis evaluation of human sperm Biomicrofluidics 8, 024102 (2014); 10.1063/1.4866851

A robotics platform for automated batch fabrication of high density, microfluidics-based DNA microarrays, with applications to single cell, multiplex assays of secreted proteins

Rev. Sci. Instrum. 82, 094301 (2011); 10.1063/1.3636077

High-throughput size-based rare cell enrichment using microscale vortices

Biomicrofluidics 5, 022206 (2011); 10.1063/1.3576780

A prototypic microfluidic platform generating stepwise concentration gradients for real-time study of cell apoptosis

Biomicrofluidics 4, 024101 (2010); 10.1063/1.3398319

Analyzing shear stress-induced alignment of actin filaments in endothelial cells with a microfluidic assay

Biomicrofluidics 4, 011103 (2010); 10.1063/1.3366720

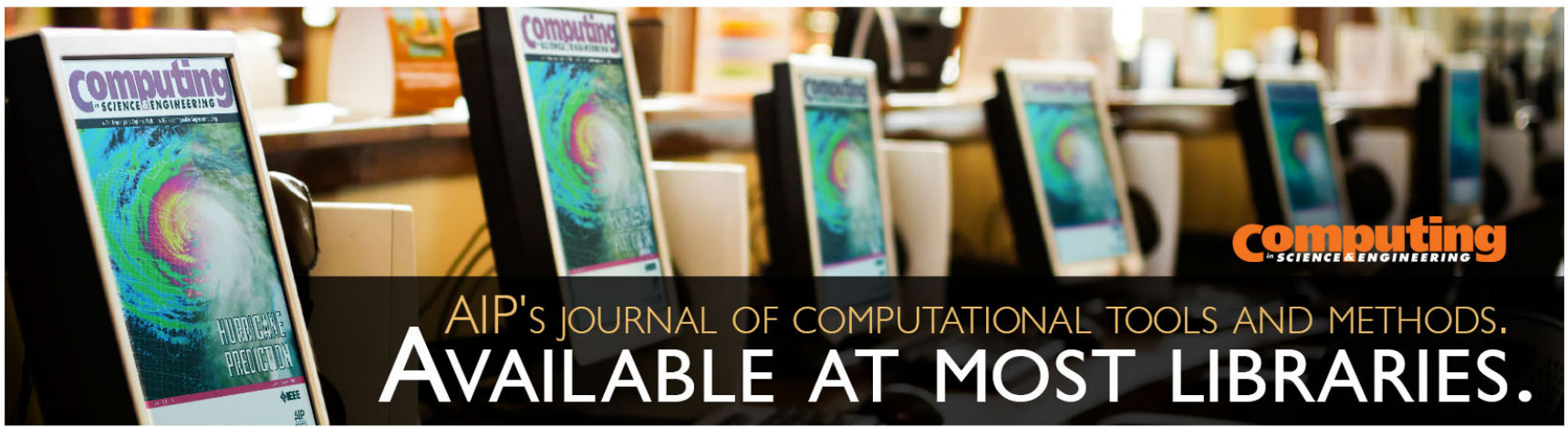




\title{
Automated single cell sorting and deposition in submicroliter drops
}

\author{
Rita Salánki, ${ }^{1,2,3}$ Tamás Gerecsei, ${ }^{3}$ Norbert Orgovan, ${ }^{2,3}$ Noémi Sándor ${ }^{4}$ Beatrix Péter, ${ }^{1,2}$ \\ Zsuzsa Bajtay, ${ }^{5}$ Anna Erdei, ${ }^{4,5}$ Robert Horvath, ${ }^{2}$ and Bálint Szabó ${ }^{2,3,6, a)}$ \\ ${ }_{1}^{1}$ Doctoral School of Molecular-and Nanotechnologies, University of Pannonia, Veszprém H-8200 Hungary \\ ${ }^{2}$ Nanobiosensorics Group, Research Centre for Natural Sciences, Institute for Technical Physics and \\ Materials Science, Konkoly Thege M. út 29-33. 1121 Budapest, Hungary \\ ${ }^{3}$ Department of Biological Physics, Eötvös University, Pázmány Péter sétány 1A, Budapest H-1117, Hungary \\ ${ }^{4}$ MTA-ELTE Immunology Research Group, Eötvös University, Budapest H-1117, Hungary \\ ${ }^{5}$ Department of Immunology, Eötvös University, Budapest H-1117, Hungary \\ ${ }^{6}$ CellSorter Company for Innovations, Erdöalja út 174, Budapest H-1037, Hungary
}

(Received 29 May 2014; accepted 10 August 2014; published online 27 August 2014)

\begin{abstract}
Automated manipulation and sorting of single cells are challenging, when intact cells are needed for further investigations, e.g., RNA or DNA sequencing. We applied a computer controlled micropipette on a microscope admitting 80 PCR (Polymerase Chain Reaction) tubes to be filled with single cells in a cycle. Due to the Laplace pressure, fluid starts to flow out from the micropipette only above a critical pressure preventing the precise control of drop volume in the submicroliter range. We found an anomalous pressure additive to the Laplace pressure that we attribute to the evaporation of the drop. We have overcome the problem of the critical dropping pressure with sequentially operated fast fluidic valves timed with a millisecond precision. Minimum drop volume was $0.4-0.7 \mu \mathrm{l}$ with a sorting speed of $15-20 \mathrm{~s}$ per cell. After picking NE$4 \mathrm{C}$ neuroectodermal mouse stem cells and human primary monocytes from a standard plastic Petri dish we could gently deposit single cells inside tiny drops. $94 \pm 3 \%$ and $54 \pm 7 \%$ of the deposited drops contained single cells for NE-4C and monocytes, respectively. $7.5 \pm 4 \%$ of the drops contained multiple cells in case of monocytes. Remaining drops were empty. Number of cells deposited in a drop could be documented by imaging the Petri dish before and after sorting. We tuned the adhesion force of cells to make the manipulation successful without the application of microstructures for trapping cells on the surface. We propose that our straightforward and flexible setup opens an avenue for single cell isolation, critically needed for the rapidly growing field of single cell biology. (C 2014 AIP Publishing LLC. [http://dx.doi.org/10.1063/1.4893922]
\end{abstract}

Up to now most DNA, RNA or proteome investigations have been performed on large cell populations. However, in the last few years focus has turned to single cell DNA and RNA analysis. ${ }^{1}$ A number of studies showed that individual cells have distinct expression profiles in their transcripts and proteins, even in seemingly homogeneous populations. ${ }^{2-4} \mathrm{~A}$ deeper understanding of a developing embryo or tumor requires information on the constituting individual cells. ${ }^{5}$ Stem cell populations also show heterogeneity with substantial functional consequences. ${ }^{6}$ Detection of rare tumor cells in the early state by monitoring circulating tumor cells (CTCs) and the analysis of disseminated tumor cells (DTCs) also require single cell isolation. ${ }^{7}$ It has become possible to obtain information on genome-wide single cell transcriptomes by the RNA-Seq analysis. ${ }^{8}$ Distinct populations of immune cells could also be detected by single cell transcriptomics. ${ }^{9}$

Although the downstream procedures of DNA or RNA analysis have been already automated, in most cases single cell isolation is not yet ready for high throughput. Individual cells are usually collected by microaspiration, micromanipulation, laser-capture microdissection, ${ }^{10}$ or flow cytometry. ${ }^{2,11,12}$ Single cell sample preparation ${ }^{13,14}$ can follow the classical protocol using sharp needles for cell isolation without enzymatic pre-treatment of the tissue. ${ }^{15}$ Single cells can

\footnotetext{
${ }^{\text {a) }}$ Author to whom correspondence should be addressed. Electronic mail: balintszabo1@gmail.com.
}

be picked up manually using a mouth pipette. It is a straightforward option ${ }^{16,17}$ but time-consuming and technically challenging. ${ }^{18,19}$ Fluidigm offers integrated devices for single cell isolation in 96-well plates and subsequent analysis. ${ }^{20}$ This system use integrated fluidic circuits $^{21}$ for trapping cells. However, high level of integration allows less control for the user in specific experiments.

Automated imaging and manual picking of cells with a micropipette on a fluorescent microscope have been realized by applying fluid flow through a microcavity array for immobilizing cells. $^{22}$ CellCelector $^{\mathrm{TM}}$ (Ref. 23) and MMI CellEctor Plus (Molecular Machines \& Industries) can select and collect cells from culture dishes on a microscope using a micropipette. Still, single cell sorting with a reasonable speed and efficiency remains uneasy applying these methods. We have reported that a micropipette controlled by computer vision allows automated single cell manipulations and sorting on a microscope. ${ }^{24} \mathrm{~A}$ similar robot for the automated breeding of single cells has been recently developed. ${ }^{25}$ This integrated instrument applies microwell arrays to immobilize cells on the surface for subsequent sorting. We consider our system being introduced in the current letter for single cell isolation and deposition more accessible for research and medical diagnostics as it can be mounted onto any standard inverted microscope available in most laboratories. Normal use of the microscope is undisturbed as the sample holder insert and the micropipette holder arm are easy to remove. 
Highly modular structure of the instrument makes it versatile and helps to fit the device to the specific application.

Previous CellSorter system published in Ref. 24 has been upgraded for automated single cell deposition (Fig. S1 a) as follows. ${ }^{26}$ The glass micropipette for picking up cells is held by a manually rotatable arm attached to a vertically motorized micromanipulator (Fig. S1 b). CellSorter insert for single cell deposition holds the $35 \mathrm{~mm}$ Petri dish in the middle with the culture to be sorted. Cells are deposited from the micropipette either onto a glass cover slip or into PCR tubes, both fixed in the insert (Fig. 1). Single cell transfer is carried out by moving the motorized stage horizontally back and forth between the Petri dish and the PCR tubes (or the cover glass).

Due to the curvature pressure of the liquid drop in air, fluid starts to flow out from the micropipette only above a critical pressure preventing the precise control of drop volume in the submicroliter range. If the capillary constant,

$$
a=\sqrt{\frac{2 \gamma}{\rho g}}
$$

is larger than the characteristic dimension of the system then gravity is negligible and surface tension $\gamma$ dominates the behavior of the liquid drop. ( $\rho$ is the density of the liquid and $g$ is the gravitational acceleration. $a=3.8 \mathrm{~mm}$ for water in air at $25^{\circ} \mathrm{C}$.) According to the Young-Laplace equation, the liquid will not drop unless the $p_{\mathrm{c}}$ critical pressure is exceeded:

$$
p_{\mathrm{c}}=\frac{2 \gamma}{R_{p}},
$$

where $R_{p}$ is the radius of the pipette. Below the critical pressure the liquid does not drop, but bulges from the pipette with a radius of curvature higher than $R_{p}$. The appearance of the critical pressure makes the control of drop volume uneasy as the liquid starts to flow with a relatively high speed, when the critical pressure is exceeded. The flow is needed to be stopped very soon after exceeding the critical

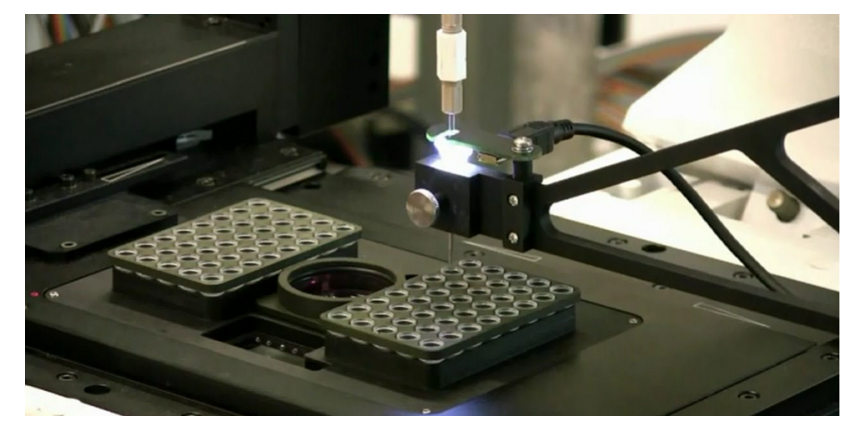

FIG. 1. Video showing the steps of automated single cell sorting and deposition with the CellSorter system. As a first step, 9 fields of view are scanned in fluorescent mode. Then, the cells are detected automatically. Software calculates the path of the micropipette (needle) useful if more than one cell is picked up in a cycle. The needle is introduced into the Petri dish and adjusted. In the first sorting run cells are deposited onto the glass cover slip. In the second run single cells arrive into the PCR tubes. Video presents the sorting of NE-4C mouse neuroectodermal stem cells labeled by the fluorescent DiI. Video was captured with a Canon HR-10 camcorder and processed using the kdenline software. Resolution: $384 \times 288$ pixels, 25 frames/s. (Multimedia view) [URL: http://dx.doi.org/10.1063/1.4893922.1] pressure, which is technically challenging as the elastic components of the fluidic system will maintain the high pressure even after closing the valve controlling the flow.

To gain insight into the dropping process we measured the curvature of the liquid surface at the tip of the capillary as a function of pressure applied to the micropipette. Curvature of the water surface was determined in the digital images captured from a side view using a stereo microscope (Fig. 2). We found that the pressure vs. curvature graph deviated from the Young-Laplace equation. We observed an additional constant pressure value independent from the curvature. We examined possible physical effects that can cause the anomalous pressure, such as the contact angle between the micropipette and the liquid, flow in the fluidic system, dependence of surface tension on drop size, ${ }^{27}$ vapor recoil, ${ }^{28,29}$ and isothermal extension of vapor in the gas phase. ${ }^{26}$ We propose that the reason of the effect is the evaporation of the liquid:

$$
p_{1}-p_{0}=\frac{2 \gamma}{R}+p_{\text {evap }}
$$

where $p_{0}$ and $p_{1}$ are the pressure far from the drop and inside the drop, respectively. $R$ is the radius of curvature of the drop, $p_{\text {evap }}=p_{\text {recoil }}+\delta p_{v}$, where $p_{\text {recoil }}$ is the pressure of vapor recoil, and $\delta p_{v}$ is the pressure difference in the gas phase built up due to the isothermal extension of vapor. We measured the rate of evaporation (Fig. S2) and found that in our experiments the contribution of vapor recoil to the anomalous pressure was negligible as compared to the pressure of the isothermal extension of vapor in the gas phase. Anomalous pressure of water could be approximated by the difference of saturated vapor pressure and the partial pressure of humidity in the laboratory. ${ }^{26}$

To test our hypothesis, we carried out experiments with the less volatile silicon oil instead of water (Fig. 2(d)). Anomalous pressure of silicon oil was in the range given by the manufacturer for the vapor pressure at $20-25^{\circ} \mathrm{C}$. Evaporation turned to be a major factor that has to be considered in microliter scale drop deposition processes. To overcome the problem of the critical dropping pressure (sum of the Laplace pressure, vapor recoil and pressure due to vapor extension) we opened both Valve 1 and Valve 2 (Fig. S1 a) with a delay between them when depositing a drop. Timing of valve openings had a precision of $1 \mathrm{~ms}$. First we opened Valve 2, then after a delay Valve 1 in order to stop abruptly the overpressure in the micropipette. Valves controlled $1 \mathrm{~mm}$ tubes with an aperture two orders of magnitude higher than the micropipette tip. This sequential programming of the valves allowed us to precisely control drop deposition in the $[0.3 ; 1.3] \mu$ l range (See Table S1).

Following the optimization of the liquid system we sorted NE-4C neuroectodermal mouse stem cells labeled with a fluorescent dye 1,1'-Dioctadecyl-3,3,3',3'-tetramethylindocarbocyanine perchlorate (DiI) $(10 \mu \mathrm{M}, 30 \mathrm{~min})$ in 5 experiments. After a $30 \mathrm{~s}$ trypsin-EDTA treatment NE-4C cells were detected manually in phase-contrast mode in the Petri dish. A total number of 120 fluorescent human monocyte cells, stained with carboxyfluorescein succinimidyl ester (CFSE) $(0.5 \mu \mathrm{M})$, were picked up in 8 experiments. We used 


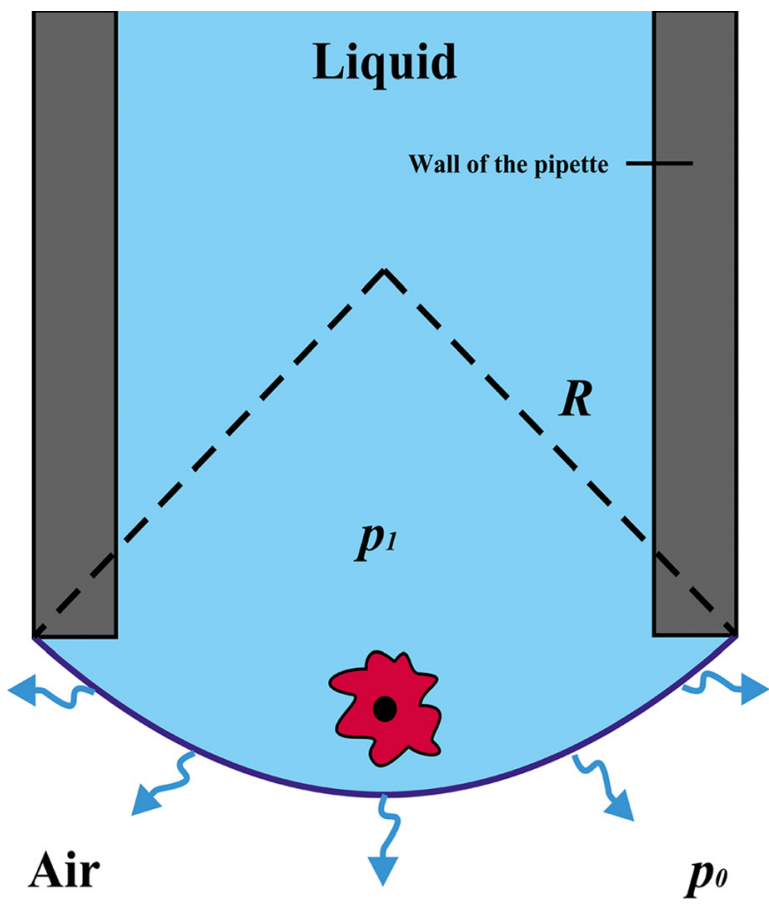

$$
p_{1}-p_{0}=\frac{2 \gamma}{R}+p_{\text {evap }}
$$

(a)
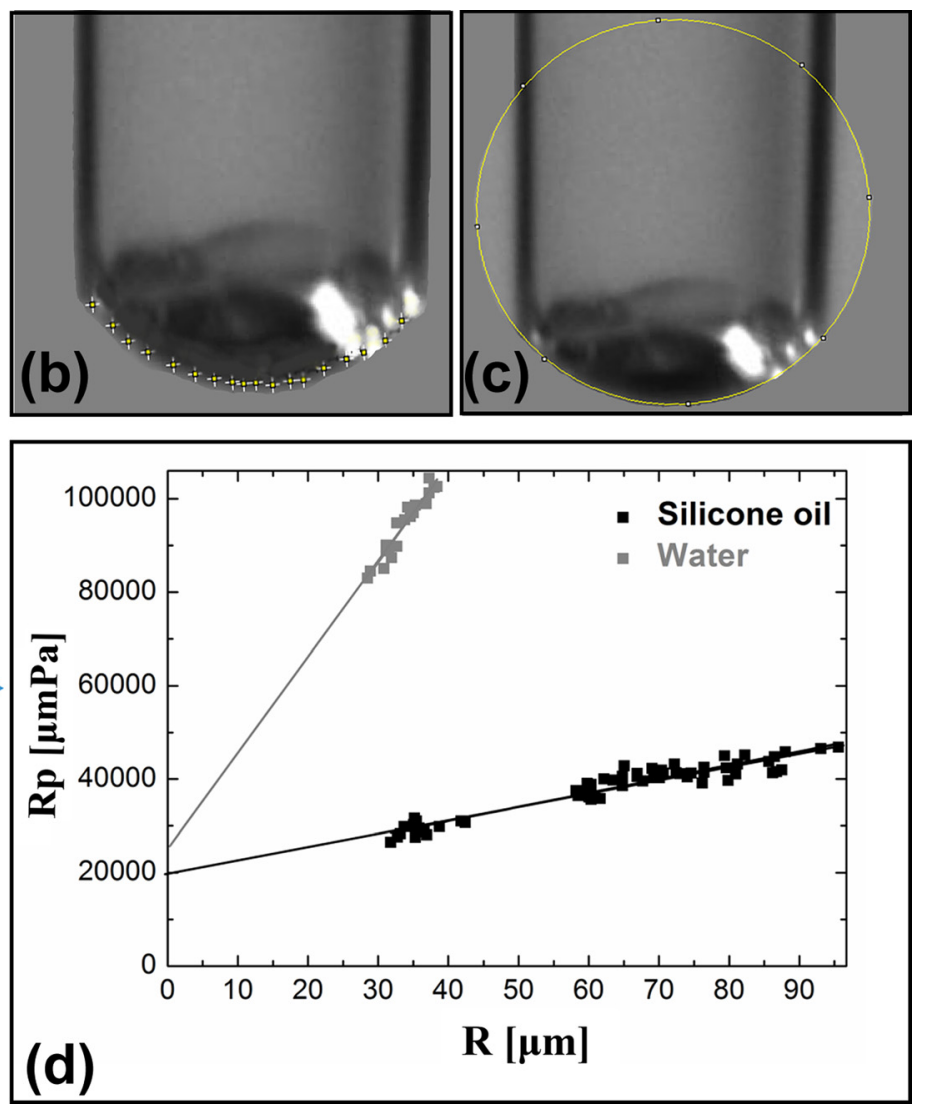

FIG. 2. We measured the curvature of the water surface at the tip of the micropipette as a function of pressure applied to the micropipette. Panel (a) shows the principle of the measurement. Pressure inside the liquid $\left(p_{1}\right)$ has to be higher than outside $\left(p_{0}\right)$ to force the liquid to bulge from the pipette according to the Young-Laplace equation. Single cell in the micropipette is represented by the frilly symbol. We fitted a circle onto the contour of the water in the side view images of the micropipette using the imageJ software (b) and (c). We found that the $p=p_{1}-p_{0}$ pressure $v s$. $R$ radius of curvature graph systematically deviated from the Young-Laplace equation. We plotted $R p v s$. $R$ in (d). It shows a linear correlation $\left(R^{2}=0.93\right)$ with a slope of $2130 \pm 135$ Pa instead of the constant function in case of water. We repeated the experiments with silicon oil and found a similar correlation $\left(\mathrm{R}^{2}=0.92\right)$ but with an order of magnitude lower slope of $297 \pm 11 \mathrm{~Pa}$ (h). We attribute the anomalous pressure to the evaporation of the drop, and describe it by an additive term in the Young-Laplace equation (a).

the cell repellent synthetic polymer poly (L-lysine)-graftpoly (ethylene glycol) co-polymer (PLL-g-PEG) at a concentration of $0.75-1.00 \mathrm{mg} / \mathrm{ml}$ instead of the trypsin-EDTA treatment to reduce the adhesion strength of monocytes to the plastic Petri dish. ${ }^{30,31}$ Vacuum pressure needs to be optimized according to the adhesion strength of the cell type if the trypsin-EDTA treatment is replaced by surface chemistry. ${ }^{32}$ Single cells were deposited one-by-one either onto a glass cover slip (Fig. 3) or into PCR tubes. Each deposited drop on the cover slip was inspected both in phase contrast and fluorescent modes to ensure the recognition of cells (Figs. 3(b) and 3(c)). We determined which drops contained zero, single or multiple cells (Table I). Total number of drops with single NE-4C cell was 93 out of 99. Single NE-4C deposition rate was $94 \pm 2 \%$ and $6 \pm 2 \%$ of the drops contained zero cells. We did not detect multiple NE-4C cells in the drops (Fig. 3(d)). In case of monocytes $54 \pm 4 \%$ of the deposited drops contained a single cell and $32 \pm 5 \%$ of them did not contain any cells (Fig. 3(e)). Drop volumes were $0.7 \pm 0.03 \mu \mathrm{l}$ for NE-4C and $0.37 \pm 0.05 \mu$ l for monocytes. The error of the mean was approximated by the weighted sample variance divided by the square root of the number of experiments.

After sorting, cells remaining in the Petri dish were scanned again. We compared the mosaic images scanned before and after sorting and identified each cell along the path of the micropipette. We inspected if the selected cell was removed from the Petri dish and also checked if additional cells were missing from the image. These results were compared to the data of cell detection in the deposited drops. We found $100 \%$ correlation in case of NE-4C cells. An empty drop always corresponded to a selected cell that remained on the surface of the Petri dish. When sorting monocytes we found minor discrepancies. $12 \pm 6 \%$ of the deposited drops were empty even when the corresponding cells were picked up by the micropipette. We attribute this effect to insufficient drop volume, i.e., these cells remained inside the micropipette. This can be eliminated by increasing the drop volume. (A drop volume up to $1 \mu \mathrm{l}$ is considered to be reasonable when using costly reagents for subsequent DNA or RNA sequencing.) We found multiple monocytes in a drop only in one single case ( $0.83 \%$ of deposited drops) when the scanned images of the culture indicated single cell. We propose that the better sorting efficiency of NE-4C cells is due to the more homogeneous nature of this laboratory cell line as compared to the inhomogeneous population of human monocytes. Variability of monocytes was further increased by the different donors. Efficiency of sorting after optimizing experimental parameters is not expected to strongly depend on cell size or shape. ${ }^{32}$

We did not investigate cell viability in this study as we carried out exhaustive viability experiment in our previous 

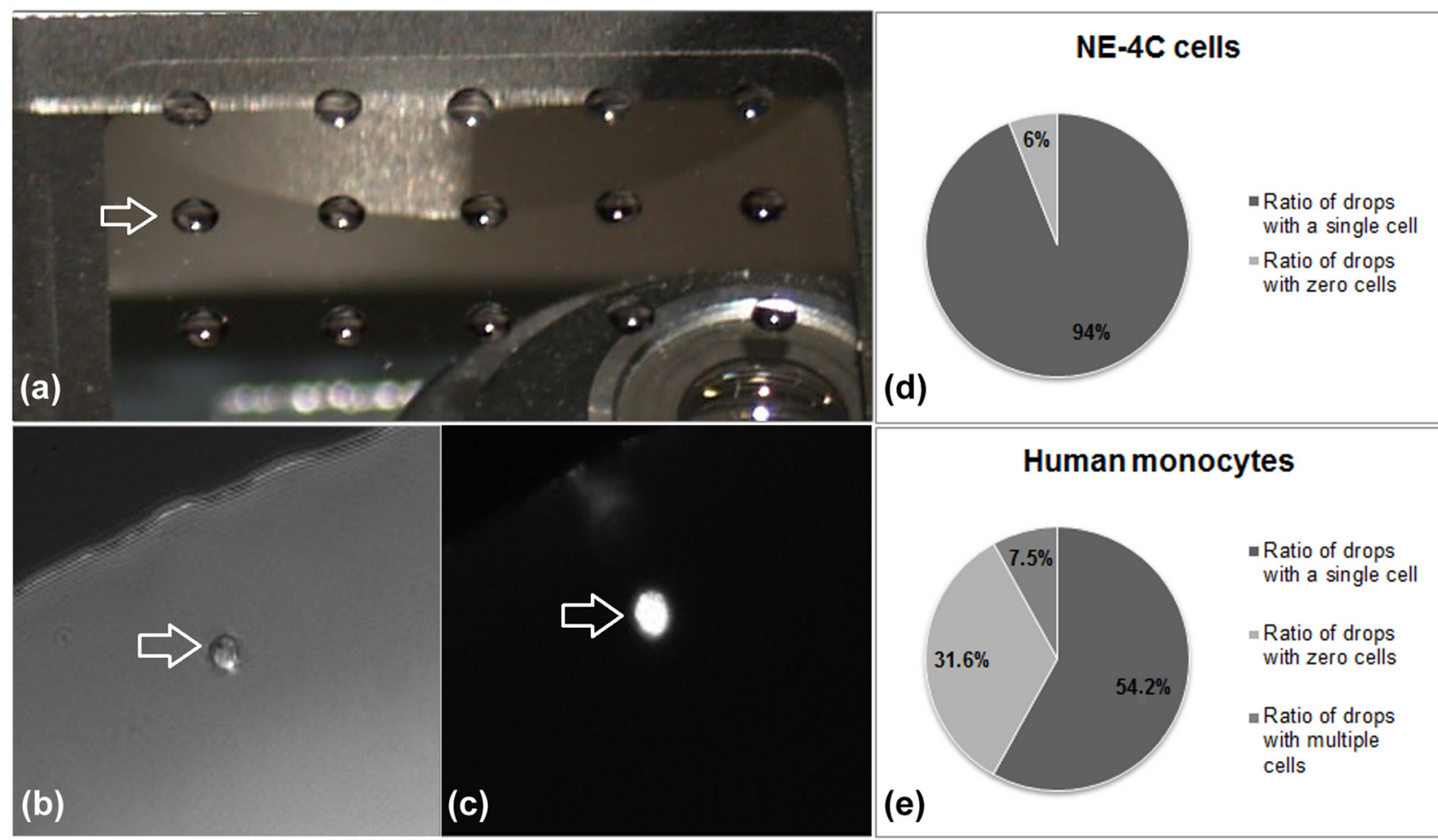

FIG. 3. Single cells in small drops. Panel (a) shows 15 drops of culture medium on a cover slip (above the objective lens) with single NE-4C cells inside after deposition. Drops are separated by $5 \mathrm{~mm}$ from each other. Phase contrast (b) and fluorescent (c) images of a single intact cell inside a drop. Arrow points to the cell inside a drop. Drop volumes were $0.7 \pm 0.03 \mu \mathrm{l}$ for NE-4C and $0.37 \pm 0.05 \mu \mathrm{l}$ for monocytes. Statistics of cell deposition calculated from Table I is shown in panel (d) and (e) for NE-4C and monocytes, respectively.

report $^{24}$ using the same system without automated cell deposition. We argue that automated cell deposition is not expected to affect cell viability when using the same vacuum and pressure parameters as in case of the manual deposition. Single cell isolation inherently can have a long term effect on cell viability which is not related to the sorting technique.

We used a device allowing computer controlled single cell manipulation in a cell culture. Due to the Laplace pressure, fluid starts to flow out from the micropipette only above a critical pressure preventing the precise control of drop volume in the submicroliter range. We found an anomalous pressure additive to the Laplace pressure that we attribute to the evaporation of the drop, i.e., vapor recoil and the pressure difference built up in the gas phase due to isothermal extension of vapor. Evaporation turned to be a major factor to be considered in microliter scale drop deposition processes. We have overcome the problem of the critical dropping pressure (sum of the Laplace pressure, vapor recoil and pressure due to the extension of vapor) by an imaginative fluidic system controlled by fast valves timed with a precision in the millisecond range. We could minimize the drop volume to reach the submicroliter regime, as it is a crucial parameter when further investigation of cells, e.g., sequencing uses expensive reagents. We tuned the surface chemistry and the adhesion

TABLE I. Result of representative sorting experiments using NE-4C cells and human monocytes. Statistics are shown in Fig. 3.

\begin{tabular}{|c|c|c|c|c|c|c|c|}
\hline Cell type & Surface & Treatment & $\begin{array}{c}\text { Number of cells } \\
\text { selected }\end{array}$ & $\begin{array}{l}\text { Number of cells } \\
\text { picked up }\end{array}$ & $\begin{array}{l}\text { Number of drops } \\
\text { with a single cell }\end{array}$ & $\begin{array}{l}\text { Number of } \\
\text { drops with } \\
\text { zero cells }\end{array}$ & $\begin{array}{c}\text { Number } \\
\text { of drops with } \\
\text { multiple cells }\end{array}$ \\
\hline \multirow{5}{*}{ NE-4C } & bare & trypsin-EDTA (30s) & 20 & 20 & 20 & 0 & 0 \\
\hline & & & 19 & 19 & 19 & 0 & 0 \\
\hline & & & 20 & 18 & 18 & 2 & 0 \\
\hline & & & 20 & 19 & 19 & 1 & 0 \\
\hline & & & 20 & 17 & 17 & 3 & 0 \\
\hline \multirow{8}{*}{$\begin{array}{l}\text { Human } \\
\text { monocyte }\end{array}$} & $1 \mathrm{mg} / \mathrm{ml}$ PLL-g-PEG & - & 18 & 13 & 6 & 5 & 2 \\
\hline & coating on plastic & & 20 & 17 & 12 & 3 & 2 \\
\hline & & & 4 & 3 & 3 & 1 & 0 \\
\hline & & & 16 & 12 & 9 & 7 & 0 \\
\hline & $0.75 \mathrm{mg} / \mathrm{ml}$ PLL-g-PEG & - & 19 & 12 & 10 & 7 & 2 \\
\hline & coating on plastic & & 20 & 11 & 10 & 9 & 1 \\
\hline & & & 20 & 14 & 13 & 6 & 1 \\
\hline & & & 3 & 3 & 2 & 0 & 1 \\
\hline
\end{tabular}


force of cells to make the manipulation successful without the application of specific microstructures for trapping single cells on the surface. Single cells were picked up from the Petri dish and deposited into PCR strips or onto glass cover slips inside tiny drops. The system also could be flexibly programmed to pick up more cells one-by-one in a cycle and deposit them into the same tube. Minimum drop volume was $0.7 \mu \mathrm{l}$ for NE-4C and $0.4 \mu \mathrm{l}$ for monocytes with a sorting speed of 15-20 s/cell. The image of each cell removed from the Petri dish was documented by the system, which informed the operator if specific tubes contain 0 or multiple cells instead of 1 . We propose that our straightforward and flexible setup with the automated micropipette opens an avenue for single cell manipulations like isolation for further investigations, e.g., DNA or RNA analysis.

We thank Dr. Zsuzsanna Környei for providing the NE4C cells. We are grateful to Professor Tamás Vicsek for establishing the microscopy lab, where most of the work was done. This work was supported by the Lendület Program of the Hung. Acad. Sci., the project TÁMOP-4.2.2/B-10/12010-0025, OTKA K104838 Hungarian national research grant, and Bolyai Scholarship of the Hung. Acad. Sci. for B.S.

R.S. performed most experiments, processed data and worked on the manuscript, T. G. carried out drop curvature measurements, N.O. and B.P. took part in the experiments, N.S. prepared the monocytes from human blood, labeled them and took part in consultations, Z.B., A.E., and R.H. contributed to the design of experiments and discussion of results, B.S. developed the instrument, analyzed experimental data and worked on the manuscript. B.S. is a founder of CellSorter, the startup company that developed the device we used in our experiments.

${ }^{1}$ V. Lecault, A. K. White, A. Singhal, and C. L. Hansen, Curr. Opin. Chem. Biol. 16, 381 (2012).

${ }^{2}$ A. Ståhlberg, C. Thomsen, D. Ruff, and P. Åman, Am. Assoc. Clin. Chem. 58, 1682 (2012).

${ }^{3}$ A. Raj, C. S. Peskin, D. Tranchina, D. Y. Vargas, and S. Tyagi, PLoS Biol. 4, e309 (2006).

${ }^{4}$ H. H. Chang, M. Hemberg, M. Barahona, D. E. Ingber, and S. Huang, Nature 453, 544 (2008).

${ }^{5}$ T. Kalisky, P. Blainey, and S. R. Quake, Annu. Rev. Genet. 45, 431 (2011).

${ }^{6}$ K. Hope and M. Bhatia, Nat. Methods 8, S36 (2011).

${ }^{7}$ N. Navin and J. Hicks, Genome Med. 3, 31 (2011).
${ }^{8}$ D. Ramsköld, S. Luo, Y. C. Wang, R. Li, O. Deng, O. Faridani, G. A. Daniels, I. Khrebtukova, J. F. Loring, L. C. Laurent, G. P. Schroth, and R. Sandberg, Nat Biotechnol. 30, 777 (2012).

${ }^{9}$ A. K. Shalek, R. Satija, X. Adiconis, R. S. Gertner, J. T. Gaublomme, R. Raychowdhury, S. Schwartz, N. Yosef, C. Malboeuf, D. Lu, J. T. Trombetta, D. Gennert, A. Gnirke, A. Goren, N. Hacohen, J. Z. Levin, H. Park, and A. Regev, Nature 498, 236 (2013).

${ }^{10}$ F. Kamme, R. Salunga, J. Yu, D. T. Tra, J. Zhu, L. Luo, A. Bittner, H. Q. Guo, N. Miller, J. Wan, and M. Erlander, J. Neurosci. 23, 3607 (2003).

${ }^{11}$ A. Ståhlberg, D. Andersson, J. Aurelius, M. Faiz, M. Pekna, M. Kubista, and M. Pekny, Nucleic Acids Res. 39, e24 (2011).

${ }^{12}$ L. Warren, D. Bryder, I. L. Weissman, and S. R. Quake, Proc. Natl. Acad. Sci. U. S. A. 103, 17807 (2006).

${ }^{13}$ S. S. Rubakhi and J. V. Sweedler, Nature Protoc. 2, 1987 (2007).

${ }^{14}$ A. Bora, S. P. Annangudi, L. J. Mille, S. S. Rubakhin, J. Forbes, N. L. Kelleher, M. U. Gillette, and J. V. Sweedler, J. Proteome Res. 7, 4992 (2008).

${ }^{15}$ S. S. Rubakhi, E. V. Romanova, P. Nemes, and J. V. Sweedler, Nat. Methods 8, S20 (2011).

${ }^{16}$ F. Tang, C. Barbacioru, Y. Wang, E. Nordman, C. Lee, N. Xu, X. Wang, J. Bodeau, B. B. Tuch, A. Siddiqui, K. Lao, and M. A. Surani, Nat. Methods 6, 377 (2009).

${ }^{17}$ K. Kurimoto, Y. Yabuta, Y. Ohinata, Y. Ono, K. D. Uno, R. G. Yamada, H. R. Ueda, and M. Saitou, Nucleic Acids Res. 34, e42 (2006).

${ }^{18}$ F. Tang, K. Lao, and M. A. Surani, Nat. Methods 8, S6 (2011).

${ }^{19}$ C. M. Hempel, K. Sugino, and S. B. Nelson, Nature Protocols 2, 2924 (2007).

${ }^{20}$ J. S. Jang, V. A. Simon, R. M. Feddersen, F. Rakhshan, D. A. Schultz, M. A. Zschunke, W. L. Lingle, C. P. Kolbert, and J. Jen, BMC Genomics 12, 144 (2011).

${ }^{21}$ J. Melin and S. R. Quake, Annu. Rev. Biophys. Biomol. Struct. 36, 213 (2007).

${ }^{22}$ M. Hosokawa, A. Arakaki, M. Takahashi, T. Mori, H. Takeyama, and T. Matsunaga, Anal. Chem. 81, 5308 (2009).

${ }^{23}$ A. Schneider, D. Spitkovsky, P. Riess, M. Molcanyi, N. Kamisetti, M. Maegele, J. Hescheler, and U. Schaefer, PLoS ONE 3, e3788 (2008).

${ }^{24}$ Z. Környei, S. Beke, T. Mihálffy, M. Jelitai, K. J. Kovács, Z. Szabó, and B. Szabó, Sci. Rep. 3, 1088 (2013).

${ }^{25}$ N. Yoshimoto, A. Kida, X. Jie, M. Kurokawa, M. Iijima, T. Niimi, A. D. Maturana, I. Nikaido, H. R. Ueda, K. Tatematsu, K. Tanizawa, A. Kondo, I. Fujii, and S. Kuroda, Sci. Rep. 3, 1191 (2013).

${ }^{26}$ See supplementary material at http://dx.doi.org/10.1063/1.4893922 for a detailed description of experimental methods; table of deposited drop volumes; and a review of possible physical effects in the background of the anomalous pressure we observed.

${ }^{27}$ R. C. Tolman, J. Chem. Phys. 17, 333 (1949).

${ }^{28}$ G. Ramon and A. Oron, J. Colloid Interface Sci. 327, 145 (2008).

${ }^{29}$ J. L. Pérez-Díaz, M. A. Álvarez-Valenzuela, and J. C. García-Prada, J. Colloid Interface Sci. 381, 180 (2012).

${ }^{30}$ N. Orgovan, B. Peter, S. Bösze, J. J. Ramsden, B. Szabó, and R. Horvath, Sci. Rep. 4, 4034 (2014).

${ }^{31}$ S. Faraasen, J. Vörös, G. Csúcs, M. Textor, H. P. Merkle, and E. Walter, Pharm. Res. 20, 237 (2003).

${ }^{32}$ R. Salánki, C. Hős, N. Orgovan, B. Péter, N. Sándor, Z. Bajtay, A. Erdei, R. Horvath, and B. Szabó, "Single cell adhesion assay using computer controlled micropipette," PLoS ONE (to be published). 